NBER WORKING PAPER SERIES

TAX COMPETITION WITH PARASITIC TAX HAVENS

Joel Slemrod

John D. Wilson

Working Paper 12225

http://www.nber.org/papers/w12225

NATIONAL BUREAU OF ECONOMIC RESEARCH

1050 Massachusetts Avenue

Cambridge, MA 02138

May 2006

We are grateful for comments on an earlier draft provided by Clemens Fuest, Andreas Haufler, and participants in seminars at the University of Copenhagen and the University of Michigan. The views expressed herein are those of the author(s) and do not necessarily reflect the views of the National Bureau of Economic Research.

C2006 by Joel Slemrod and John D. Wilson. All rights reserved. Short sections of text, not to exceed two paragraphs, may be quoted without explicit permission provided that full credit, including (@) notice, is given to the source. 
Tax Competition and Parasitic Tax Havens

Joel Slemrod and John D. Wilson

NBER Working Paper No. 12225

May 2006

JEL No. H26, H87

\begin{abstract}
We develop a tax competition framework in which some jurisdictions, called tax havens, are parasitic on the revenues of other countries. The havens use real resources to help companies camouflage their home-country tax avoidance, and countries use resources in an attempt to limit the transfer of tax revenues to the havens. The equilibrium price for this service depends on the demand and supply for such protection. Recognizing that taxes on wage income are also evaded, we solve for the equilibrium tax rates on mobile capital and immobile labor, and we demonstrate that the full or partial elimination of tax havens would improve welfare in non-haven countries, in part because countries would be induced to increase their tax rates, which they have set at inefficiently low levels in an attempt to attract mobile capital. We also demonstrate that the smaller countries choose to become tax havens, and we show that the abolishment of a sufficiently small number of the relatively large havens leaves all countries better off, including the remaining havens.
\end{abstract}

\title{
Joel Slemrod
}

Stephen M. Ross School of Business

University of Michigan

701 Tappan Street, Room W7719

Ann Arbor, MI 48109-1234

and NBER

jslemrod@umich.edu

John D. Wilson

Department of Economics

Michigan State University

W. Owen Hall

East Lansing, MI 48824-1038

wilsonjd@msu.edu 


\section{Introduction}

Although there is no universally accepted definition, OECD (1998) provides a useful definition of a tax haven as a jurisdiction that imposes no or only nominal taxes itself and offers itself as a place to be used by non-residents to escape tax in their country of residence. A tax haven can offer this service because it has laws or administrative practices that prevent the effective exchange of information on taxpayers benefiting from the low-tax jurisdiction. ${ }^{1}$ In this paper, we refer to the intent of such jurisdictions as being "parasitic" on the tax revenues of the non-haven countries. Our purpose is to develop a theory of tax havens and tax competition that explains why countries are, and should be, concerned about the detrimental effects of havens on their citizen's welfare.

Policy actions by OECD countries reflect this concern. Before the 1998 OECD report, action against tax havens was predominantly unilateral, as exemplified by the introduction in 1962 of the U.S. Subpart F provisions that addressed so-called passive income earned in tax haven countries and not distributed to the United States. ${ }^{2}$ Later many OECD countries enacted domestic tax rules designed to lessen the attractiveness of tax avoidance and evasion though tax havens.

The OECD report concludes that "governments cannot stand back while their tax bases are eroded through the actions of countries which offer taxpayers ways to exploit tax havens [and preferential regimes] to reduce the tax that would otherwise be payable to them.” (p. 37). It offers a long list of recommendations concerning domestic legislation, tax treaties, and international cooperation. In the last category is a recommendation to produce a list of tax-haven countries that would enable non-haven countries to coordinate their responses to the problems

\footnotetext{
${ }^{1}$ The OECD report distinguished tax havens from cases in which countries that raise significant revenues from the income tax but have preferential tax regimes for certain kinds of income, generally restricted to non-residents. ${ }^{2}$ This history is recounted in Eden and Kudrle (2005).
} 
created by the havens and to "encourage these jurisdictions to reexamine their policies." (p. 57)

In 2000, the OECD followed up by publishing the names of 35 countries called "non-cooperating tax havens," which were given one year to enact fundamental reform of their tax systems and broaden the exchange of information with tax authorities or face economic sanctions. By 2005, almost all of the blacklisted tax havens had signed the OECD's Memorandum of Understanding agreeing to transparency and exchange of information. ${ }^{3}$

Notably, the 35 designated tax havens are invariably small. Their average population is 284,000 , and is 116,000 if one excludes the only two designated countries (Liberia and Panama) whose population exceeds one million. Although the 35 tax havens represent over 15 percent of the world's countries, their total population comprises just 0.150 percent of the world's population (0.058 percent excluding Liberia and Panama). Of the 35 designated tax havens, 27 are island nations. ${ }^{4}$

In sharp contrast to the longstanding concern about the deleterious effects of havens, recent normative economic theory has focused on a potentially beneficial role for tax havens. The starting point is the well-known result that, under certain conditions, a small, open economy should levy no distorting tax on mobile factors such as capital. The intuition behind this result is straightforward. All taxes levied in this economy will ultimately be borne by the immobile factors. Given that, it is better to levy taxes directly on the immobile factors; attempting to tax the mobile factors will not change the incidence but will, unlike taxes levied directly on the immobile factors, drive away the mobile capital, thus reducing the productivity and therefore the

\footnotetext{
${ }^{3}$ Public U.S. support for the OECD initiative flagged after 2000, as exemplified by statements by the Secretary of the Treasury suggesting that the U.S. government was no longer committed to fighting the tax havens. In addition, some other OECD countries such as Ireland, Luxembourg, and Switzerland, have haven-like aspects of their own tax systems, and several other member countries privilege certain tax havens through double tax treaties and other preferential tax regimes. (Eden and Kudrle 2005, p. 123).

${ }^{4}$ Hines (2005) presents more information about tax havens, and analyses their recent economic performance.
} 
pre-tax return to the immobile factors. See Gordon (1986) and Bucovetsky and Wilson (1991)

for demonstrations that small open economies should not levy distorting source-based taxes.

Countries do, however, levy distorting taxes on mobile capital. Much of the recent theoretical literature conceives of tax havens as a device to save these countries from themselves, by providing them with a way to move toward the non-distorting tax regime they should, but for some reason cannot explicitly, enact. ${ }^{5}$ For example, in Hong and Smart (2005), citizens of hightax countries can benefit from haven-related tax planning because it allows them to tax domestic entrepreneurs (in a lump-sum way) without driving away mobile multinational capital. The haven exists only as a construct allowing the parent to borrow from the low-tax affiliate and deduct the interest; the interest received by the haven affiliate is tax-free. The presence of the haven reduces the (distorting) effective marginal tax rate for any given statutory tax rate.

Peralta, Wauthy, and van Ypersele (2003) also assume that countries cannot directly discriminate the rate of profit taxation of mobile and immobile firms, but a government may optimally decide not to enforce the arm's length principle of transfer pricing in order to host a multinational firm while setting high profit taxes on domestic firms. Similarly, Becker and Fuest (2005) demonstrate that if immobile and mobile firms must be taxed at the same rate, then the government may wish to alter other aspects of the tax code to reduce the effective taxation of the mobile firms, including the use of a pure profits tax and the degree to which capital costs are tax deductible.

\footnotetext{
${ }^{5}$ A separate literature examines the issue of whether countries would benefit from international agreements that potentially lessen tax competition by restricting the degree to which countries can provide preferential tax treatment to relatively mobile factors. The results are mixed. See Janeba and Peters (1999), Keen (2001), Janeba and Smart (2003) Wilson (2005), and Bucovetsky and Haufler (2005). Most recently, Marceau, Mongrain, and Wilson (2006) demonstrate that rules against preferential treatment enable small countries to compete away mobile capital from larger countries, but that non-preferential regimes are still preferable.
} 
The idea that countries should welcome tax havens as a way to overcome their inability to explicitly differentiate the effective tax rate on mobile and immobile capital flies in the face of the fact that governments of non-haven countries often expend considerable resources to limit the effect of haven transactions on their own tax revenue. It suggests that these countries do not view havens as a way to overcome exogenous, perhaps politically-motivated, constraints on their tax policy.

This paper develops a model of tax competition in the presence of parasitic tax havens that explains and justifies existing initiatives to limit haven activities. As should be expected, tax havens lead to the wasteful expenditure of resources, both by firms in their participation in havens and by governments in their attempts to enforce their tax codes. In addition, tax havens worsen tax competition problems by causing countries to further reduce their tax rates below levels that are efficient from the viewpoint of all countries combined. Either full or partial elimination of havens is found to be welfare-improving. Indeed, initiatives to limit some, but not all, havens can be designed to leave all countries better off, including the remaining havens. To demonstrate this last possibility, we model the decision to become a haven and, in so doing, demonstrate that small countries have a greater incentive to become havens.

Our model is designed to capture the role in the world economy of the small, mostly, island economies that act as tax havens. For this reason we do not develop a model of symmetric, identical countries, but rather a model in which some countries act as havens and other countries do not - the former are parasitic on the revenues of the latter, in a way we make explicit. Second, we model the real resources that are used up as companies camouflage their tax avoidance and evasion operations and high-tax governments attempt to limit the transfer of revenues to the havens. To address this issue, we model tax havens as juridical entrepreneurs 
that sell protection from national taxation, resulting in what Palan (2002) calls the "commercialization of state sovereignty." The equilibrium price for this service depends on the demand for such protection, which in turn depends on the tax system, including the resources devoted to tax enforcement by the non-haven countries, and on the technology available to the parasitic havens.

As noted above, the degree to which countries choose to tax mobile capital relative to immobile factors is critical to arguments that tax havens may be beneficial. Standard tax competition models do not adequately confront this issue, because they typically assume that only the tax on mobile capital is endogenously determined. In contrast, our analysis addresses this issue directly by assuming that tax evasion is also a problem in the collection of taxes on immobile labor. In this manner, we justify a role for capital taxation in a small, open economy. In addition to examining restrictions on the number of havens, we explicitly model the decentralized use of enforcement activities. The notion that tax enforcement policy is a separate instrument of tax policy that can play a role in tax competition has been recognized in the work of Cremer and Gahvari $(1997,2000)$. An important insight from this work is that each country has an incentive to enforce its tax base suboptimally, because the resulting reduction in the effective tax rate causes more of the mobile tax base to locate within its borders. Whereas this result may also hold in the current model, we explicitly examine the mix of statutory rates and enforcement levels used to finance a given public good level. Our conclusion is that countries would be better off if they agreed to increase their tax rates and lower enforcement. Doing so would raise the demand for the evasion-facilitating services from tax havens, which would raise the effective price of these services and thereby discourage tax evasion. Countries 
fail to take into account this "cost externality" when choosing how vigorously to enforce their tax codes.

The plan of this paper is as follows. We develop the model in the next section, and then devote Section 3 to deriving the equilibrium tax policies for each country. Section 4 demonstrates that eliminating tax havens raises public good levels and improves welfare. The partial elimination of havens is addressed in Section 5, and Section 6 analyzes inefficiencies in tax enforcement activities. In Section 7, the model is extended to include the endogenous determination of the number of tax havens. Section 8 concludes.

\section{The Model}

We extend a standard model of tax competition to include tax havens. ${ }^{6}$ The economy contains of a large number of countries, each containing a fixed number of identical residents, $L_{i}$ for country $i$. Each resident possesses one unit of labor and $k^{*}$ units of capital. The utility function is denoted $u(x, g)$, where $x$ is private consumption and $g$ is consumption of a publiclyprovided private good, both of which are normal goods. For brevity, we refer to the latter good as the "public good."

The capital employed by country $i$ is $K_{i}$, with $K_{i}-k^{*} L_{i}$ representing imports of capital. Competitive firms use a constant-returns technology to transform these inputs into a single output. This output is sold to consumers in the form of the private consumption good, and to the government for use as the sole input in the production of the public good. Taxes on immobile labor and mobile capital are used to finance the public good. Although countries differ in size, we will specify a constant-returns technology for collecting and evading taxes that yields equilibrium tax policies that are independent of country size.

\footnotetext{
${ }^{6}$ See Wilson (1999) for a review of the tax competition literature.
} 
The taxation of capital takes the form of a territorial tax on "taxable business income," defined below. In particular, each government taxes only the capital income earned within its borders. $^{7}$ This assumption is standard in the tax competition literature, and reflects the difficulties that home countries face in effectively taxing foreign-source income.

In standard models that feature perfect competition and constant returns to scale in production, the number of competitive firms is typically indeterminate and irrelevant. For the present case, however, we wish to model tax avoidance at the firm level. Consequently, we assume that investors create firms using one unit of capital per firm, and then these firms hire labor and decide how much income to shelter in tax havens. Each firm has access to the same production technology and therefore employs the same labor and produces the same output. Firms differ, however, in the cost of setting up operations in a tax haven, as described by a parameter, $\theta$.

We assume that firms purchase from tax havens "services" that facilitate the concealment of taxable income. The mechanism through which the havens facilitate tax avoidance is left unspecified. The unit price of concealment services, $p$, is a function of worldwide purchases of these services, $C$. In other words, there is a well-defined inverse supply function for concealment services, $p=p(C)$, which may be infinitely elastic or upward-sloping. An interpretation is that there are many "competitive" havens, each of which prices its services at marginal cost. ${ }^{8}$

\footnotetext{
${ }^{7}$ This assumption allows us to sidestep the question of whether havens can benefit capital-exporting countries by reducing the tax collected by host countries, letting the home country collect more revenue for any given excess burden. See Hines and Rice (1994) for an elaboration of this argument.

${ }^{8}$ Note that this specification may be interpreted more generally by assuming that the production of concealment services requires the use of not just a tax haven, but also the aid of "accountant services" located in a firm's country of residence. More formally, one could posit a production process whereby accountant and haven services serve as intermediate inputs in the production of concealment services. If there were constant costs in the provision of accountant services (to abstract from issues related to country size, which do not seem important in this context), then all countries will face the same world supply curve for concealment services.
} 
For now, we treat the number of jurisdictions that are tax havens as exogenously fixed. If a country is not a tax haven, then it is simply referred to as "a country." Section 7 endogenizes this number and shows that an upward-sloping supply curve may be generated by country size differences: the concealment price $p$ must rise to induce larger countries to become havens. In either case, we assume that any net imports or exports of capital between havens and countries are unimportant, allowing us to follow standard tax competition models by treating the capital employed per worker as fixed for the set of countries as a whole.

The timing of events is as follows. First, each country's government chooses its tax rates and expenditures on tax enforcement. Next, firms are formed, with capital moving across countries to ensure that a firm's expected income, calculated net of taxes, labor expenditures, and expenditures on the concealment of taxable income, are the same everywhere. This expected income is denoted $r$, which may be interpreted as the expected after-tax return on capital. The realized return is random because investors do not yet know the value of their firms' $\theta$ 's (e.g., tax avoidance may require legal research to be carried out by lawyers with uncertain skills). However, when making their investment decisions, investors correctly anticipate wages in each country and the opportunities for concealing income. In the next stage, $\theta$ is revealed and firms purchase labor and concealment services. Finally, output is produced and sold, taxes are paid, and the public good is provided.

Output produced in a country may then be written $K f(L / K)$, where the production function $f$ relates a firm's output per unit of capital to the labor-capital ratio that it employs, and country subscripts are dropped where doing so would cause no confusion. The income earned by a firm's investors before taxes are paid (or evaded) is given by the before-tax return on capital, $R=$ 
$f(L / K)-W(L / K)(L / K)$, where $W(L / K)$ is the country's equilibrium wage, which is declining in the labor-capital ratio. Note that $R$ is an increasing function of $L / K$. Inverting this function yields the capital demand function, $k(R)$, expressed per unit of labor. With $R$ and $W$ both related to $L / K$, we can also define a factor-price frontier, $W(R)$, which satisfies the requirement that equilibrium profits (output minus labor and capital costs) equal zero.

Capital income is taxed at the statutory rate $t$, but a firm can lower the tax base, and therefore the average effective tax rate, by first incurring the "set-up cost," $\theta R$, which we take to be a fixed fraction of firm size as measured by income, $R .^{9}$ For each dollar of income, $s(c, b)$ can be shielded from taxes by purchasing $c$ units of concealment services at the cost $p c$, where $b$ represents the government's enforcement expenditures per unit of capital. ${ }^{10}$ This function is increasing and strictly concave in $c$, and declining and convex in $b$, with $s(0, b)=0$ and $l>s(c$, b) $>0$ for all positive $c$. In particular, some taxes are paid even when $b=0$, although the amount may be small (costless "moral suasion"). ${ }^{11}$ Finally, we assume that $\partial^{2} \mathrm{~s} / \partial \mathrm{c} \partial \mathrm{b}<0$, implying that an increase in $b$ reduces the marginal productivity of $c$ in income-shifting activities, thereby reducing a firm's optimal purchases of concealment services. Unless specifically indicated, we will consider interior solutions for both taxpayers and the government, i.e., where $b$ and $c$ are positive.

For a firm that takes advantage of this income-shifting opportunity, after-tax profits are

\footnotetext{
${ }^{9}$ Making the set-up cost proportional to revenue $R$ simplifies the algebra, because the subsequent purchases of concealment services are also proportional to $R$; however, our results are not sensitive to this particular specification. ${ }^{10}$ Equivalently, we could specify a cost function $c(s, b)$. Whereas firms are assumed to directly choose $c$ in the current paper, a previous draft assumed that they chose $s$, given a nonlinear price function, $p(s)$, designed by tax havens to induce firms to choose $s$ efficiently. The two specifications are effectively equivalent.

${ }^{11}$ This specification avoids discontinuities at $b=0$, where $s(c, b)$ goes to zero as $c$ goes to zero for $b>0$, but $s(c, b)$ $=1$ for $b=0$ and $c>0$. We assume that $s(c, b)$ is twice continuously differentiable.
} 


$$
\widetilde{r}=R[1-(p c+\theta)-t(1-s-\beta(p c+\theta)],
$$

where the tilde distinguishes this return from its expected value, $r$, calculated prior to the realization of $\theta$, and $\beta$ denotes the fraction of payments to tax havens that is tax deductible, which is assumed to be fixed by law. This fraction is meant to reflect the deductibility of variable costs under the U.S. tax code, combined with the possibility that firms may wish to shield some payments to havens from the tax authority, in an attempt to avoid detection. Our main results will not depend on the value of $\beta$. Without loss of generality, we assume here that income shifted to a tax haven is not taxed at all by the haven.

The firm chooses $s$ to maximize $\widetilde{r}$, yielding the first-order condition,

$$
\frac{t}{1-t \beta} \frac{\partial s}{\partial c}=p
$$

where subscripts denote partial derivatives. As an example, suppose that $s=c^{\gamma}, \gamma<1$, for a given $b$ and a value of $c$ in some neighborhood of zero. In this case, (2) implies that $d c / d t$ is increasing in $t$, with $d c / d t=0$ at $t=0$. Alternatively, let $s=\int_{0}^{c} \frac{1}{\psi+x} d x, \psi>0$, again for a given $b$ and small values of $c$. For small values of $t$, we then have a corner solution, where $c=0$. But for any given $t$, no matter how small, we may choose $\psi$ sufficiently small to ensure that the chosen $c$ is positive, in which case (2) implies that $d c / d t=1 / p .^{12} \quad$ This last example suggests that the marginal deadweight loss from an increase in $t$ can be substantial at low values of $t$,

\footnotetext{
${ }^{12}$ We cannot choose $\psi=0$, because then the integral defining $\mathrm{c}$ does not exist.
} 
measured in terms of the resources "wasted" on tax evasion. As we next see, however, few firms will choose to evade taxes at small values of $t$.

By determining concealment purchases, (2) also determines the benefit a firm receives from participating in a haven—not counting the setup cost $\theta$ - expressed per dollar of income as follows:

$$
\Theta=t s-(1-t \beta) p c
$$

This benefit determines the number of firms that participate in a haven. In particular, all firms with $\theta<\Theta$ choose to participate, whereas those with $\theta>\Theta$ do not. Letting $G(\theta)$ denote the continuous distribution function for $\theta$, the number of firms participating in a tax haven, summed over all countries, is $G(\Theta) k^{*} \sum_{i \in N} L_{i}$, where $N$ is the set of countries. With each of these firms purchasing $c R$ units of concealment services, aggregate purchases are $C=c R G(\Theta) k^{*} \sum_{i \in N} L_{i}$.

Letting $\alpha=G(\Theta)$ denote the share of firms that shift income to havens, we may rearrange (1) and take its expected value to obtain the pre-tax return, $R$, as the sum of the expected after-tax return, $r$, the effective tax rate, $T$, and the social costs associated with capital income tax shifting, $D^{K}$

$$
R=r+T+D^{K}
$$

where

$$
T=t R(1-\alpha(s+\beta(p c+E(\theta / \theta<\Theta)))-b
$$


and

$$
D^{K}=R(\alpha(p c+E(\theta / \theta<\Theta)))+b
$$

where $E(\theta / \theta<\Theta)$ is the expected value of $\theta$, conditional on participation in a tax haven. The social cost of capital taxation per unit of capital, $D^{K}$, consists of government expenditures on enforcement, $b$, plus the expected costs incurred by a firm to evade taxes. Using (3)-(6), together with the optimizing behavior of taxpayers, we may define the functions, $T=T(R, t, b, p)$ and $D^{K}$ $=D^{K}(R, t, b, p)$.

The costs included in $D^{K}$ are social costs not only from the given country's viewpoint, but also from the viewpoint of all countries combined, because they represent expenditures on real resources. The cost of the investment distortion to the country is not included in $D^{K}$, because it is not a social cost from the viewpoint of all countries--firms that do not locate there choose to locate in other countries.

For future use it will be helpful to invert the function $T$ to obtain $t=t(R, T, b, p)$. By substituting this function into $D^{K}(R, t, b, p)$ and using the determination of $R$ given by (4), we may redefine the function $D^{K}$ as $D^{K}(r, T, b, p)$. The derivative, $D_{T}^{K}(r, T, b, p)$, is positive, because a rise in the effective rate $T$ requires an increase in the statutory rate, which induces more firms to participate in havens, and existing participants to increase their concealment purchases. In addition, the higher statutory rate raises the before-tax return, $R$, which further increases $D^{K}(r, T, b, p)$, because more income is subject to evasion. Note finally that a welfaremaximizing country will choose an enforcement level $b$ to minimize $D^{K}(r, T, b, p)$. In other words, it will choose the combination of $t$ and $b$ that minimizes this deadweight loss, subject to the constraint that $t$ and $b$ yield the chosen effect rate $T$. In the case of an interior solution, we 
may use the first-order condition, $D_{b}^{K}(r, T, b, p)=0$, to define a relation between the optimal value of $b$ and $T$, given the $r$ and $p$ faced by the country.

To introduce labor taxation into the model, it is essential that we recognize the administrative costs involved in taxing labor. If this tax could be costlessly collected, then governments would clearly prefer taxes on labor to taxes on capital, which distort investment and, in a small economy open to capital but not labor movement, have similar incidence. Even if we introduced a labor-leisure distortion into the model, the labor tax would still be preferred; as shown by Gordon (1986) and Bucovetsky and Wilson (1991), a small open economy should not tax capital income at source if a tax on (immobile) labor income is available, regardless of the labor supply elasticity. If, for political reasons, government officials must tax wage and capital income at the same statutory rate, then they would have an incentive to allow tax havens to exist, thereby lowering the effective tax on capital towards zero. ${ }^{13}$

These arguments ignore the administrative costs involved in taxing wage income, including those associated with tax evasion. Standard models predict that workers respond to taxation in the same way that capital owners respond in the model described above: they incur costs in order to evade. (See Slemrod and Yitzhaki, 2002, for a review.)

Because our main focus is on tax havens, we use a reduced-form specification of the consequences of evasion of taxes on wage income that presumes implicitly that wage earners are willing to incur costs to evade and that governments are willing to incur costs to curtail evasion. Assume that taxing wage income at the statutory rate $\tau$ implies an effective rate of $\Gamma(W, \tau)$ per unit of labor, and raises $\Gamma(W, \tau) L$ dollars of revenue, where the country's labor supply, $L$, is again assumed to be fixed. This effective rate is defined similarly to the effective tax rate on

\footnotetext{
${ }^{13}$ This is the logic underlying the "tax-havens-are-good" literature discussed in Section 1.
} 
capital taxation, $T(R, t, b, p)$, and has similar properties. In particular, $\Gamma(W, \tau)$ is increasing in both arguments, with $\partial^{2} \Gamma / \partial W \partial \tau>0$ and $\Gamma(0, \tau)=\Gamma(W, 0)=0$. But, unlike our treatment of capital taxation, we do not explicitly model the enforcement activities that are expended in order to ensure that taxes are remitted to the government. Rather, we assume that they are optimized, given the chosen values of $\tau$. Section 5 will generalize the model by recognizing the possible relation between the evasion of wage taxes and the statutory tax rate on capital income

Tax evasion activities by wage earners, along with enforcement activities intended to combat tax evasion, create a deadweight loss per unit of labor, denoted $D^{L}$. By inverting the effective-tax-rate function to obtain the relation, $\tau=\tau(W, I)$, we may define a relation between this deadweight loss and the values of $W$ and $\Gamma: D^{L}=D^{L}(W, \Gamma)$. This function is increasing in $W$ and $\Gamma$ at positive values of $\Gamma$. To ensure some use of wage taxation in equilibrium, we assume that $\partial D^{L} / \partial \Gamma=0$ at $\Gamma=0$. The interpretation here is that a small tax rate on wage income (effective and statutory) creates no first-order incentive to evade taxes.

\section{Equilibrium Tax Policies}

This section demonstrates that countries choose to tax capital, despite its mobility. The optimization problem for a government consists of maximizing the utility of its residents, $u(x, g)$, subject to three constraints. The government budget constraint requires that the cost of the public good be equal to tax revenue net of enforcement expenditures. Assuming constant returns to scale in the provision of the public good, this cost may be written $g L$, and the budget constraint may then be expressed, in per capita terms, as follows:

$$
g=T k(R)+\Gamma
$$


A resident's budget constraint takes the form,

$$
x=r k^{*}+W(R)-\Gamma-D^{L}(W(R), \Gamma) .
$$

The deadweight loss from capital taxation, $D^{K}$, enters this constraint indirectly by reducing the wage, $W(R)$, through its positive impact on the cost of capital:

$$
R=r+T+D^{K}(r, T, b, p),
$$

and the reduction in capital use due to the increased cost of capital. In contrast, both $\Gamma$ and $D^{L}$ directly reduce the income available to a resident for consumption, reflecting expenditures on income-shifting activities.

Replacing $x$ and $g$ with the expressions given by (7) and (8), and using (9), yields an unconstrained optimization problem with $T, b$, and $\Gamma$ as the control variables, which together determine the statutory tax rates, $t$ and $\tau$. We have chosen to work with the effective tax rates as control variables, because doing so yields more easily interpretable first-order conditions. The first-order conditions for $T$ and $\Gamma$ may be written in a form that equates the marginal benefit of $g$, $u_{x} / u_{g}$, to the marginal cost, $M C^{i}$, where $i=T$ or $\Gamma$, depending on the method of finance. As stressed in Mayshar (1991) and Slemrod and Yitzhaki (2002), in an optimal tax system the marginal efficiency cost of funds should not depend on how these funds are obtained at the margin. In other words, $M C^{T}=M C^{\Gamma}$, assuming no corner solutions. We make this assumption, 
and later prove it. Throughout the analysis, we assume that enforcement $b$ is optimally set, where $D_{b}^{K}(r, T, b, p)=0$, for $b>0$, as previously explained.

The first-order condition for $\Gamma$ is derived by differentiating (7) and (8) with respect to $\Gamma$ to obtain the marginal rate of transformation between $x$ and $g$, and then equating this quantity to the marginal rate of substitution between $x$ and $g$, yielding:

$$
\frac{u_{g}}{u_{x}}=1+D_{\Gamma}^{L} \equiv M C^{\Gamma}
$$

Thus, the evasion of payments on wage income increases the marginal cost of the public good, $M C^{\Gamma}$, by an amount equal to the marginal deadweight loss from the higher effective tax on wage income, $D_{\Gamma}^{L}$.

Whereas the taxation of wage income has no impact on factor prices $W$ and $R$ (because we are taxing a fixed factor), increasing the statutory tax rate on capital income causes $R$ to rise and $W$ to fall, so that capital continues to earn the after-tax return that is available elsewhere. To obtain the marginal rate of transformation between $\mathrm{x}$ and $\mathrm{g}$, we may differentiate (7) and (8) with respect to $T$ and take the ratio of these derivatives, $(d x / d T) / d g / d T)$. Equating this expression to the marginal rate of substitution yields the first-order condition for $T$ :

$$
\frac{u_{g}}{u_{x}}=\frac{\left(1-D_{W}^{L}\right)\left(1+D_{T}^{K}\right)}{1-\frac{T}{R} \varepsilon\left(1+D_{T}^{K}\right)} \equiv M C^{T},
$$


where $\varepsilon=-k^{\prime}(R / k)>0$, denoting the capital demand elasticity (measured positively), and use is made of the factor-price derivative, $W^{\prime}(R)=-k$.

Recall that in the standard tax competition model (i.e., where tax evasion is absent), the marginal cost of $g, M C^{T}$, exceeds the marginal resource cost (normalized to equal one) because each country treats as a cost the outflow of capital resulting from a rise in its tax rate on capital. This outflow represents a positive externality for other countries, in the form of capital inflows, suggesting that public good provision is inefficiently low (more on this below).

But, when tax havens exist, (11) reflects the fact that increasing $T$ through a higher statutory rate on capital income, $t$, makes concealment services more valuable to firms. As a result, they respond by increasing their purchases of concealment services and hiding more income: $c$ and $s$ rise. In addition, more firms participate in tax shelters, so that $\alpha$ rises. Finally, the resulting rise in the return $R$ represents additional income that is subject to evasion, further increasing the amount of capital income tax evasion. The marginal loss term, $D_{T}^{K}$, reflects all of these effects. This marginal loss increases the marginal impact of $T$ on the cost of capital, thereby contributing in two ways to the marginal cost of the public good. First, it raises the capital outflow resulting from a rise in $T$, as shown by the term multiplying the capital demand elasticity, $\varepsilon$. Second, $D_{T}^{K}$ appears in the numerator of (11), because the higher cost of capital is borne by workers in the form of a lower wage rate.

In contrast, the presence of tax evasion in the labor market tends to reduce $M C^{T}$. The higher $T$ reduces the equilibrium wage, $W(R)$, thereby lowering the deadweight loss resulting 
from this tax evasion. Simply stated, there is less evasion if there is less wage income. This

effect is given by the term $D_{W}^{L}$ in (11). ${ }^{14}$

Since $M C^{\Gamma}=M C^{T}$ under an optimal tax system, we have

$$
\frac{\left(1-D_{W}^{L}\right)\left(1+D_{T}^{K}\right)}{1-\frac{T}{R} \varepsilon\left(1+D_{T}^{K}\right)}=1+M D_{\Gamma}^{L}>1
$$

This equality is now used to show that the optimal $t$ and $\tau$ are indeed positive.

Proposition 1. Countries tax both labor and capital.

Proof. If $t=0$ initially (in which case $T=0$ and $b=0$ ), there are no incentives to evade capital income taxes, and so no firms participate in tax havens, implying $D^{K}=0$. Since $\alpha=c=0$ initially, the expression for $D^{K}$ given by (6) tells us that marginal increases in $t$ and $R$ have no impact on $D^{K}$ when $t=0$. Thus, $D_{T}^{K}=0$ in (11), where this derivative includes the rise in $t$ and the resulting increase in $R$. Because $T \varepsilon$ also equals zero at $t=0$, the positive value of $D_{W}^{L}$ in (11) then implies that $M C^{T}<1$ at $t=0$. Thus, $M C^{T}<M C^{\Gamma}$, implying that welfare can be increased by raising $t$ above zero and reducing $\tau$. Under our assumptions, $M C^{T}>M C^{\Gamma}=1$ if $\tau=$ 0, implying that the optimal $\tau$ must also be positive. Q.E.D.

\footnotetext{
${ }^{14}$ It appears to be theoretically possible for $M C^{T}$ to fall short of the marginal resource cost of the public good (equal to one), but this will not happen under an optimal tax system.
} 
The critical point here is that a small capital tax causes a negative first-order efficiency loss. The first-order loss associated with a capital outflow, $T \varepsilon$, is clearly zero when evaluated at $t$ $=T=0$. Previous examples showed that $d c / d t=0$ at $t=0$. Even if $d c / d t$ were positive, a marginal rise in $t$ from zero would cause only a tiny number of firms to purchase a tiny amount of concealment services, and these firms would be the ones that incur a negligible fixed cost to enter the tax-haven market (i.e., they have small values of $\theta$ ). Thus, there is also no first-order loss from the evasion of capital taxes when $t$ is raised above zero. But by raising the cost of capital, this capital tax lowers the equilibrium wage, $W(R)$, which reduces the amount of evasion in the labor market, creating a first-order efficiency gain. For this reason, the marginal cost of the public good is actually less than one when it is financed by increasing $t$ from zero.

Looked at another way, a small capital tax must be beneficial because its depressing effect on wages represents a transfer of income from lightly-evaded capital income (due to the low $t$ ) to more heavily evaded wage income, lowering the overall deadweight loss from tax evasion.

As capital taxation substitutes further for wage taxation in the financing of the public good, the efficiency losses from capital tax evasion and capital outflows both increase, causing $M C^{T}$ to rise and eventually exceed $M C^{\Gamma}$. With (12) determining the optimal mix of statutory tax rates (given that $b$ is optimally set at each $t$ ), we may define the marginal cost curve, $M C(g, p)$, for countries facing concealment-service price $p$, where we hold fixed $R$ and $W(R)$ at their market-clearing levels (i.e., where $k(R)=k^{*}$ ). At low levels of $g$, this curve must be upwardsloping, with increases in $g$ financed by a combination of increases the two tax rates, as uniquely determined by (12). To avoid possible anomalies resulting from violations of these properties, 
we henceforth assume that they extend to the range of $g$ considered in this paper. To shorten the exposition, we also assume that $b$ is positive, unless stated otherwise.

Figure 1 depicts the equilibrium mix of taxes as the intersection of the two marginal cost curves, $M C^{T}$ and $M C^{\Gamma}$ (ignore the other line for now), holding fixed $g$. The horizontal axis measures the share of the given level of public expenditures that is financed with the capital tax. At the unique intersection, countries are choosing their optimal tax systems. In Figure 2, $g^{*}$ denotes the equilibrium public good level, where the marginal benefit (MB) and marginal cost (MC) curves cross.

\section{The Undesirability of Tax Havens}

We now demonstrate that tax havens are undesirable. Our argument proceeds by eliminating tax havens and showing that, for two reasons, welfare increases. First, each country's residents directly benefit from the productive use of resources that were previously used for income shifting and tax enforcement activities. Second, the marginal cost of the public good declines, inducing countries to increase their public good levels. We shall show that competition for capital implies that the equilibrium public good level remains below the level that is optimal from the combined viewpoint of all countries. Thus, eliminating tax havens moves the public good level closer to this optimum, increasing welfare.

Proposition 2. The elimination of tax havens raises the equilibrium level of the public good and increases country welfare. 
Proof. Eliminating havens does not alter factor prices $R$ and $W(R)$ (determined by the equilibrium condition, $k(R)=k^{*}$ ). For a given $g$, however, the resulting efficiency gains raise private consumption, $x$.

But $g$ does change. If it remained at its initial value, then the rise in $x$ would increase the marginal benefit of $g$, given by $u_{g} / u_{x}$, since $g$ is a normal good. But for a given value of $T$, the absence of havens would eliminate the marginal deadweight loss terms, $D_{T}^{K}$ and $D_{R}^{K}$, on the right side of (11), causing $M C^{T}$ to fall (recall that $R$ does not change). Then, as shown in Figure 1, the decline in $M C^{T}$ would move its intersection down the $M C^{\Gamma}$ curve, thereby reducing the common value of this marginal cost. With the marginal benefit now greater than the marginal cost of public good provision, equilibrium would be restored through an increase in every country's $g$, as shown in Fig. 2.

To conclude the proof, we show that this increase in $g$ in every country raises each country's welfare. Set $g$ at its new equilibrium level, where

$$
\frac{u_{g}}{u_{x}}=\frac{1-D_{W}^{L}}{1-\frac{T}{R} \varepsilon}=1+D_{\Gamma}^{L}>1,
$$

given that both $t$ and $\tau$ are optimized. When all countries raise $g$ by increasing these two taxes, no country's capital stock changes, and so the wage rate also remains fixed. Thus, there is no loss in revenue from capital outflows and no change in the deadweight loss from wage taxation, that is, the terms $T \varepsilon / R$ and $D_{W}^{L}$ drop out of (13), lowering the marginal cost expression given by the middle term to one. Countries therefore provide $g$ at the level where increasing $g$ by a unit in every country, financed with their chosen increases in $t$ and $\tau$, would provide a marginal benefit, $u_{g} / u_{x}$, that exceeded the marginal cost. It follows that the positive impact of the elimination of tax havens on each country's $g$ raises welfare. Q.E.D 
Proposition 2 may appear to run counter to arguments in favor of tax havens, which are based on a presumption that havens lower the effective tax rate on mobile capital, thereby reducing the investment distortions associated with a tax system that constrains income from immobile and mobile factors to be taxed at similar, or identical, statutory rates. This argument is not relevant here, because we have endogenized the relative values of these statutory rates by allowing them to be optimally set in an unconstrained way. A lower effective tax on capital can be achieved simply by reducing the statutory rate, and doing so is preferable to allowing tax havens to flourish, because tax havens raise the cost of collecting any given level of taxes on capital income.

Even if we simply impose the requirement that capital and wage income be taxed at the same statutory rate, it might still be the case that eliminating tax havens is beneficial. Given our assumption that taxes on wage income induce evasion, the optimal tax system involves some taxation of capital income, and so governments will engage in costly enforcement activities to collect this tax. Eliminating havens reduces or eliminates these enforcement costs, but the resulting effective tax rate on capital is presumably too high when capital and wage income must face the same statutory tax rate. These two considerations work in opposite directions, so in the political-constraint scenario we cannot say for sure whether tax havens are good or bad. However, the next section demonstrates that it is always desirable to eliminate some havens, and this result extends to the case in which all income is taxed at the same statutory rate. 


\section{Partial Elimination of Tax Havens}

Partial elimination of tax havens raises some issues that complete elimination does not. In particular, if some, but not all, tax havens are eliminated, then countries are affected by the reduction in the supply of concealment services, because the equilibrium price of these services

will increase (see Section 7). The question thus becomes whether country residents are better off when $p$ increases. This section answers that question in the affirmative.

To establish this result, we shall need to place restrictions on the form of the incomeshifting function, $s(c, b)$, but these restrictions will enable us to demonstrate that the desirability of restricting the operations of tax havens extends to cases where wage tax evasion depends on the statutory tax rate on capital income. Gordon and MacKie-Mason (1995) emphasize this linkage. In their model, if capital income is not taxed, then taxpayers have the incentive to recharacterize and report wage income as capital income for tax purposes. More generally, this incentive depends on the excess of the wage tax over the capital tax. Gordon and MacKieMason use this observation to demonstrate that the optimal tax on capital is positive for a small open economy. In our model, the desirability of capital taxation is reinforced.

This new feature is incorporated into the model by introducing the capital tax, $t$, as an argument in the deadweight loss function for wage taxation, $D^{L}=D^{L}(W, \Gamma, t)$. In particular, this loss function is declining in $t$ at those combinations of the three arguments that imply a statutory rate $\tau>t$. We shall assume that $\tau>t$ in equilibrium, reflecting the difficulties involved in taxing mobile factors. For simplicity, we then assume $D^{L}(W, \Gamma, t)$ does not vary with $t$ in the (out-of-equilibrium) case where $\tau<t$. With the evasion technology thus generalized, we may modify the rule for the optimal $t$, given by (11), as follows: 


$$
\frac{u_{g}}{u_{x}}=\frac{\left(1-D_{W}^{L}\right)\left(1+D_{T}^{K}\right)+D_{t}^{L} \frac{d t}{d T}}{1-\frac{T}{R} \varepsilon\left(1+D_{T}^{K}\right)} \equiv M C^{T},
$$

where $d t / d T$ now indicates the rise in $t$ needed to increase the effective rate $T$ a unit. Equation (14) shows that the marginal cost of public good provision will be less than one when financed with a rise in $t$ from some low level, not only because highly-taxed wage income is reduced, but now also because the rise in $t$ directly reduces incentives to evade taxes on wage income.

Turning to the income-shifting function, $s(c, b)$, we now assume that it can be written as $s(c /(\gamma+b))$, where $s(0)=0, s^{\prime}()>0$, and $\gamma$ is a positive parameter. For small values of this parameter, it is then approximately true that equal percentage changes in concealment services (c) and enforcement expenditures (b) leave unaffected the amount of income shifting. To shorten notation, define $B=\gamma+b$, in which case we describe $s(c / B)$ as homogeneous of degree zero in $c$ and "adjusted enforcement." Then the first-order condition (2) of a firm's optimal choice of $c$ becomes:

$$
\frac{t}{1-t \beta} s^{\prime}\left(\frac{c}{B}\right)=p B
$$

With this additional structure, we prove the following lemma in the Appendix:

Lemma 1. For the homogeneous income-shifting function, if $b>0$ in equilibrium, then a rise in the unit price of concealment services, holding fixed the after-tax return, $r$, raises a country's welfare. 
This result is easily understood. By (15), the increase in $p$ enables countries to reduce their enforcement expenditures, $b$, without causing the amount of concealment services to rise. Since $b$ is financed out of the government budget, countries are then able to increase public good provision or reduce the wage tax.

The behavioral response of countries to a higher $p$ creates externalities through their impact on the after-tax return, $r$. The proof of Proposition 3 in the Appendix shows that the increase in $p$ increases the equilibrium public good level by shifting down the marginal cost of funds curve, and shifting up the marginal benefit curve. In Figure 2, the new equilibrium public good level is denoted $g^{* *}$. Countries respond to the rise in $p$ by increasing public good provision and their taxation of labor and capital, which drives down $r$. In the standard tax competition story, welfare rises in every country because no country experiences a capital outflow when their taxes all rise by identical amounts. Instead, $r$ falls enough to keep the before-tax return $R$ unchanged, thereby eliminating incentives for capital to exit any country.

But when tax havens are present, the reduction in $r$ may increase the costs associated with these havens. In particular, the unit tax $t R$ falls as $r$ declines, requiring a higher $t$ to offset the revenue loss. But this higher statutory rate increases incentives to shift income through the use of tax havens. As a result, it appears possible for welfare to fall as each country's public good level rises above the equilibrium value. In other words, we cannot rule out the possibility that the equilibrium level of public good provision is inefficiently high.

Three factors work against this argument, however. First, the higher $t$ reduces the evasion of taxes on wage income (the Gordon and MacKie-Mason argument). Second, if havens are reduced to a sufficiently small number, then the higher $t$ no longer has much effect on tax haven activities, relative to the fiscal externalities that lead to public good underprovision. Thus, 
we can say that a large enough elimination of havens must improve welfare (assuming that $b$ remains positive, as required for Lemma 1). Finally, our previous examples suggest that the fiscal externalities leading to public good underprovision will in many cases outweigh the new "evasion externality" identified above, provided the capital tax is not too high. In particular, recall our examples where $d c / d t=0$ at $t=0$. In this case small taxes create no first-order demand for concealment services, and therefore no first-order participation in tax havens. As a result, the efficiency losses from the fiscal externalities dominate those from capital tax evasion if $t$ is not too high.

Thus, underprovision of public good remains a relevant problem in economies with both tax competition and tax havens, and reducing the number of tax havens is beneficial because it increases public good provision. Using Lemma 1, we may then state:

Proposition 3. Assume the homogeneous income-shifting function, and consider an equilibrium where $b>0$. By increasing the concealment price $p$, a reduction in the number of havens causes all countries to increase their public good provision. Provided tax competition leads to underprovision of the public good, this reduction in havens must raise welfare.

As the number of havens is reduced, raising $p$, it becomes increasingly likely that a corner solution will be reached, where governments realize it is not optimal to pay for enforcement activities because the private costs associated with tax evasion have become sufficiently high. In this case, our proof of Proposition 3 is no longer valid. ${ }^{15}$ However, the

\footnotetext{
${ }^{15}$ The proof builds on Lemma 1 by showing that an increase in $p$ enables $b$ to be reduced so that additional tax revenue is generated, without any changes in incentives to evade taxes, and a reduction in the marginal deadweight loss from the financing of an additional unit of $g$. For income-shifting functions that do not satisfy our homogeneity
} 
possibility that havens could be limited this much is perhaps farfetched. We return to the issue of haven reduction in Section 7.

\section{Enforcement Expenditures}

Instead of attempting to control the number of tax havens, countries could instead coordinate their enforcement activities. If public goods are underprovided, then mandating stricter enforcement might improve welfare in part by leading to additional public good provision. However, such mandates would also affect the mix of taxes and enforcement used to finance the chosen public good level. We next argue that the equilibrium mix is inefficient when the supply curve for concealment services is upward-sloping (i.e., $\left.p^{\prime}(C)>0\right)$. In this case, a higher tax rate on capital or a lower enforcement level will increase the equilibrium price of concealment services by increasing the demand for these services. We have already seen that this higher price raises welfare in all countries. One country's policy change causes only a small change in $p$, but this price change impacts a large number of countries, making its welfare effect non-negligible. This "cost externality" is not found in standard tax competition models. Here, it implies that countries finance their chosen public good supply with an inefficiently high level of enforcement, because they do not take into account that a lower level will, by raising $p$, benefit all countries.

The next proposition provides an exact sense in which enforcement is inefficiently high. The assumption that $p^{\prime}(C)>0$ ensures that an increase in the demand for concealment services raises $p$, whereas the other three assumptions were previously shown to imply that welfare rises with $p$.

assumption, we would need to rule out the possibility that Proposition 3 is reversed by asymmetries in the incentive effects associated with marginal changes in $p$ and $b$. 
Proposition 4. Assume that: (1) the evasion technology implies a homogeneous incomeshifting function; (2) $b>0$ in the initial equilibrium; (3) tax competition leads to underprovision of the public good; and (4) the supply curve for concealment services is upward-sloping. Then countries enforce their capital tax collections too stringently. In particular, if each country reduces the enforcement level $b$ by the same amount, while adjusting its capital tax t to keep its cost of capital unchanged, given the equilibrium $r$ and $p$, then $p$ will rise and all countries will be better off.

Proof. Suppose first that that a single country raises the statutory rate $t$ but then lowers enforcement $b$ enough to keep $T+D^{K}$ unchanged, thereby leaving the before-tax return, $R$, unaffected. In this case, there will be no capital inflow or outflow and therefore none of the resulting externalities. However, both the rise in $t$ and fall in $b$ induce firms to demand more concealment services, driving up the price. If we implement this policy change in every country, $p$ will rise and, as we have seen, all countries will benefit from the higher price, through both its negative impact on the social costs of tax evasion (Lemma 1), and its positive impact on public good supplies. Q.E.D.

The policy perturbation described in this proposition does not necessarily keep public good supplies fixed, because the proposition encompasses the case where increasing the tax rate on capital reduces evasion of wage taxes. But we can then adjust the wage tax to keep $g$ fixed, giving us a welfare-improving perturbation that finances the equilibrium level of $g$ with less 
enforcement. In this sense, the financing of the equilibrium public good level is too “enforcement-intensive".

This proposition qualifies results in previous literature saying that governments compete for capital by reducing their enforcement activities (e.g., Cremer and Gahvari 1997, 2000), and it arises from cost externalities not found in the standard tax competition model. If the supply curve for concealment services were completely elastic $\left(p^{\prime}(C)=0\right)$, then these externalities would disappear, and so capital taxes would be collected using the level of enforcement that is socially optimal for the system of countries as a whole. But our analysis of haven formation in the next section suggests that an upward-sloping supply curve is the norm.

\section{Country Size and Tax Havens}

We now model the formation of tax havens, in a way that generates an upward-sloping supply curve and explains why relatively small countries are more likely to become tax havens. The basic idea is that the costs incurred in becoming a haven grow with country size, whereas the benefit remains largely unchanged because a country's productivity in the production of concealment services is unrelated to its size. In other words, what enables a jurisdiction to provide concealment services (i.e., facilitate income shifting) is that it is $a$ jurisdiction, not that it is a large jurisdiction.

Consider the conditions for a symmetric equilibrium, under which all (non-haven) countries choose the same policies. We continue to assume that each country is small enough to have no significant impact on the after-tax return $r$ and concealment price $p$. Thus, each country optimizes, conditional on these prices, and their optimal policies imply a before-tax return, $R(p$, $r$ ). In equilibrium, $p$ and $r$ must then equate demand with supply in the capital market: 


$$
k(R(p, r))=k^{*}
$$

Given $p$, (16) determines a market-clearing $r$, denoted $r(p)$. Using this function, we may then define a single country's per-capita demand for concealment services as a function of $p$ alone, $d(p)$. Letting $Y_{i}(p)$ denote haven $i$ 's total supply of concealment services, the market-clearing condition for $p$ is:

$$
\sum_{i \in N} L_{i} d(p)=\sum_{i \in H} Y_{i}(p)
$$

where $N$ is the set of (non-haven) countries and $H$ is the set of havens.

If countries are free to maximize welfare by choosing whether to become havens, then havens are formed until residents in the marginal haven receive the same utility as those in countries. In a symmetric equilibrium, utilities are identical across countries. Using the function, $r(p)$, we let $v^{n}(p)$ denote this common utility. In contrast, we will argue that in some cases the benefit of becoming a haven falls with country size. Thus, define $v^{i}(p)$ as utility for residents of country $i$, if it is a haven, where country size increases with $i$. If $i *$ denotes the marginal country, we then have the following equilibrium condition:

$$
v^{n}(p)=v^{i^{*}}(p)
$$

Consider now the determination of these utilities. Non-haven countries are free to choose any desired tax system. Given the assumptions of constant returns to scale in private and 
public production, along with constant returns in tax evasion and enforcement (as previously specified, for example), the optimal tax system does not depend on the size of the country. Thus, the maximum value of utility is independent of country $i$ 's population level, $L_{i}$, in which case the maximized sum of utilities, $L_{i} v^{n}(p)$, is linear in country size.

Suppose now that a country becomes a tax haven. As a result, it lowers its statutory tax rate on capital to what would otherwise be an inefficiently low level, which in the prior analysis we have taken to be zero. Ignoring for now the benefits flowing from the sale of concealment services, we may let $v^{*}(p)$ denote the new optimized value of utility, where $v^{*}(p)<v^{n}(p)$, due to the use of a suboptimal tax system. Once again, this change will not depend on country size, given our constant-returns assumptions. Thus, the total cost of becoming a haven is $L_{i}\left[v^{n}(p)\right.$ $\left.v^{*}(p)\right]$, which is linear in size.

Those countries that choose to become havens receive a benefit from the sale of concealment services that depends critically on the production function for concealment services. We assume that each tax haven government provides an indivisible input, $e$ (e.g., the haven "legal system"), which competitive firms (e.g., banks) combine with capital $K^{\mathrm{c}}$ and labor $L^{c}$ to produce concealment services equal to $c\left(e, K^{c}, L^{c}\right)$. We shall next consider production functions that exhibit decreasing returns to scale, corresponding to upward-sloping country supply curves for concealment services $\left(p^{\prime}(C)>0\right)$, and then we discuss the constant-returns case.

If a country becomes a haven, then its cost of capital is $R=r(p)$, because it does not tax capital. Assume that decreasing returns limit the size of concealment production, so that havens also produce the private good. Then the wage is given by the factor-price frontier for private good production: $W=W(r(p))$. Thus, all concealment-producing firms will face the same input prices, regardless of the size of the haven in which they operate. It follows that they will all 
choose the same inputs and produce the same quantities of concealment services, independently of country size. Decreasing returns to scale implies that this production of concealment services generates profits, which are also independent of country size. The haven government may then tax these profits away, depending on the relative administrative costs involved in doing so.

Profits that are not taxed go to the country's residents. In either case, the haven residents ultimately benefit from the profits that concealment-service producing firms make, and this total benefit is independent of haven size.

However, in larger havens there are lower profits per resident. In contrast, we have shown that the per-resident cost of becoming a haven is independent of country size. Thus, it is the smaller countries that will choose to become havens. Using the previous notation, we have $v^{i}(p)>v^{n}(p)$ for $i$ below some cut-off point $i^{*}$ that satisfies condition (18). The world supply curve, $p(C)$, is upward-sloping because a higher price induces larger countries to become tax havens. This mechanism contrasts to the case of a fixed number of havens, where a higher price would simply induce existing havens to produce more concealment services.

Decreasing returns may be interpreted as the result of the increasing difficulty of shielding income from tax authorities as the size of a haven grows. In other words, we not only have decreasing returns at the individual firm level, as represented by the income-shifting function, $s(c, b)$, but also at the level of a haven, represented by the increasing cost incurred in providing another "effective unit" of concealment services.

If we instead assume constant returns to scale in the production of concealment services, then it can easily be shown that all countries are indifferent about becoming havens. ${ }^{16}$ As a result, the supply curve for concealment services is infinitely elastic. However, this case has a

\footnotetext{
${ }^{16}$ This result assumes that the input $e$ is either costlessly provided, or the cost of its provision increases linearly with haven size.
} 
property that seems counterfactual: each haven specializes in the production of haven services, which it sells to countries in return for the private good. This property may be simply explained. Since constant-return producers of haven services earn no profits, the benefit from becoming a haven takes the form of a higher wage. But if havens also produced the private good, then they could eliminate haven production without altering the wage; immobile labor and mobile capital would merely be re-deployed to private production. There would then be no benefit from haven production. Thus the equilibrium price of concealment services must rise to a level at which countries specializing in haven services offer wages above the level at which private-good producers would break even.

We close by relating this model of haven formation to our previous results. Proposition 1 clearly extends to the case of endogenous havens, because it concerns the tax policies chosen by (non-haven) countries. In the constant-cost case described above, where all countries and havens have the same utilities, Proposition 2 implies that the elimination of havens makes everyone better off, regardless of whether they initially resided in countries or havens. But with decreasing returns, residents of former small havens may be worse off, that is, the gain in country welfare may not be sufficient to compensate for the relatively high utilities previously received by the residents of small havens.

Proposition 3 considers an exogenous reduction in the number of tax havens, with the resulting reduction in the supply of concealment services raising the equilibrium price of these services. This supply reduction occurs in both the decreasing- and constant-returns cases (noting that havens specialize in producing only concealment services in the latter case). We may assume that the initial set of havens is either exogenous or endogenously determined, as modeled in this section. For the endogenous-haven case, Proposition 3 tells us that a sufficiently small 
reduction in havens will make everyone better off and nobody worse off, provided the larger havens are eliminated first. The largest haven did not benefit from haven activities, so it will be better off when these activities are eliminated and it takes advantage of the welfare gains associated with the higher $p$ charged by the remaining havens. But these remaining havens also benefit from this higher price. Thus, everyone is better off. This result provides a possible explanation for why international agreements might easily restrict the formation of havens by some small amount, whereas large restrictions are not feasible.

Proposition 4 clearly extends to the endogenous-haven case. If enforcement is reduced and the statutory rate increased, then the higher $p$ not only benefits countries, but it is also clearly to the advantage of havens. Thus, everyone in the world economy should desire less enforcement and higher statutory rates.

Our analysis could be extended in various directions without altering the basic argument for why small countries become havens. We could allow public inputs, $e$, to vary, while assuming that the production function $c\left(e, K^{c}, L^{c}\right)$ exhibits decreasing returns in all inputs. On the cost side, we might introduce costs other than those associated with a suboptimal tax system. For example, the "concealment industry" could be viewed as supplanting the production of intermediate inputs that enhance the productivity of private good production. To the extent that this productivity loss grows with the size of the country, small countries would have a further advantage in becoming havens.

\section{Conclusion}

Unless territorial capital income taxes are dominated by other taxes, it is optimal for countries to devote resources to defend this revenue base. Tax haven jurisdictions make this 
more difficult by, for a fee, facilitating tax avoidance in the form of income shifting. As tax rates grow, the incentives to pay such a fee also grow, aggravating the problem of tax competition and thereby putting further downward pressure on equilibrium tax rates. Our analysis justifies concerns about the prevalence of tax havens. We have shown that the elimination of havens makes all countries better off if they are not currently tax havens. By explicitly incorporating the decision of a country to become a haven, however, we have seen that smaller havens may be worse off if forced to give up their haven status. Whereas the elimination of a sufficiently small number of havens will leave all countries better off, the analysis points to the potential difficulties involved in eliminating large numbers of havens, including small ones. A task for future research would be to explore ways to coordinate further reductions in tax havens. 


\section{Appendix}

Proof of Lemma 1. Applying the envelope theorem, we know that the impact of a rise in $p$ on a country's welfare does not depend on how the common values of $b$ and $t$ change, since they are initially optimized. In particular, we may compute the welfare change by holding $t$ fixed as $p$ rises, and adjusting $b$ in any way we find convenient; the welfare effect will be the same regardless of how we choose to change $b$. Since (15) tells us that $s$ and $c / B$ stay fixed if $p B$ (and $t$ ) does not change, let us therefore reduce $b$ enough to keep $p B$ fixed as $p$ rises, so that:

$$
\frac{d B}{d p}=-\frac{B}{p}
$$

The constancy of $p B$ and $c / B$ also implies no change in $p c$, and along with the constancy of $s$, we can conclude that the number of firms participating in havens stays fixed. It follows that the only reason that the effective rate $T$ changes is that enforcement expenditures decline (see (6)). The resulting fall in $T$ creates a surplus in the government budget, which can then be used to reduce the wage tax. But with $r^{e}$ and $R$ unchanged (the change in $b$ alone does not affect $R$ ), there is then a rise in private income, $x=r^{e} k^{*}+w(R)\left(1-\Gamma-D^{L}\right)$, increasing country welfare. Q.E.D.

Proof of Proposition 3. We need to show that the increasing $p$ raises welfare. Consider first the policy response described in the proof of Lemma 1 , where $b$ is reduced as $p$ rises so that $p B$ stays constant. We know from the proof of Lemma 1 that $T$ rises, only because $b$ falls. As a preliminary step, hold $g$ fixed by taking the revenue generated from the reduced enforcement expenditures and essentially throwing it away: the lower $b$ in the expression for $T$ given by (5) is 
replaced with $b+w$, where waste $w$ is sufficient to keep $T$ unchanged. Despite this waste, we next show that the marginal cost of public good provision is lower than before and, therefore, countries have an incentive to increase their public good levels, holding $w$ fixed. Eliminating the waste $w$ enables taxes to be reduced, further lowering the marginal cost of public good provision at the initial $g$. Moreover, the lower taxes increase private consumption, $x$, which increases the marginal benefit of $g, M B=u_{x} / u_{g}$ (assuming $g$ is a normal good). As shown in Figure 2, the optimal level of public good provision rises to $g * *$. Under our assumptions, this greater provision improves welfare.

Consider first the impact of the changes in $p$ and $b$ on the capital-tax-financed marginal cost of the public good, $M C^{T}$ in (11). By (15), the constancy of $p B$ implies no change in $c / B$ and, consequently, no change in income-shifting, $s(c / B)$, no change in its derivative, and no change in concealment expenditures, $p c$. Again using (15), we can also conclude that the marginal impact of $t$ on $c / B$ and hence $s$ will be unaffected by these changes in $p$ and $B$. Although the lower $B$ implies that $c$ will fall less in response to the tax-induced fall in $c / B$, the change in $p c$ will remain the same, given the higher $p$. Given these results, neither the number of firms participating in havens, nor the marginal impact of $t$ on these firms, will change. Collecting all of these results, we find that there is no change in the marginal cost of the public good if it is financed at the margin with a rise in the statutory rate $t$.

On the other hand, the higher $p$ means that a unit rise in $b$ will increase the right side of (15) more than before, leading to a greater fall in $c / B$ and therefore greater fall in $s$. We may therefore conclude that the marginal cost of the public good is lower than before the price change, if it is financed with increased enforcement at the margin, holding fixed the statutory tax 
rates. Let $M C^{b}$ denote this marginal cost. Of course, there is no change when the financing comes from the wage tax. Thus, we have

$$
M C^{b}<M C^{T}=M C^{\Gamma}
$$

The important implication of this result is that the marginal cost of the public good has not risen (assuming optimal financing), although the fall in $b$ has generated additional revenue (denoted $w$ per unit of capital above). As explained above, this surplus in the government budget can be used to lower the tax rates, which further reduces the marginal cost of public good provision at the initial $g$, while raising the marginal benefit. The resulting rise in the equilibrium $g$ increases welfare. As explained above, the higher $g$ further increases welfare. Q.E.D. 


\section{References}

Bucovetsky, Sam and Andreas Haufler. 2005. "Tax Competition with Endogenous Mobility of Firms: Should Tax Loopholes for Multinationals be Closed?’ Mimeo, York University, May.

Bucovetsky, Sam and John D. Wilson. 1991. "Tax Competition with Two Tax Instruments.” Regional Science and Urban Economics 21:333-50.

Cremer, Helmuth and Fahrouz Gahvari. 1997. "Tax Competition and Tax Evasion.” Mimeo. Nordic Journal of Political Economy 24: 89-104.

Cremer, Helmuth and Fahrouz Gahvari. 2000. "Tax Evasion, Fiscal Competition, and Economic Integration.” European Economic Review 44: 1633-57.

Eden, Lorraine and Robert T. Kudrle. 2005. "Tax Havens: Renegade States in the International Tax Regime?” Law \& Policy 27(1): 100-127.

Elitzur, Ramy and Jack Mintz. 1996. "Transfer Pricing Rules and Corporate Tax Competition.” Journal of Public Economics 60(3): 410-22.

Gordon, Roger H. 1986. "Taxation of Investment and Saving in the World Economy." American Economic Review 76: 1086-1102. 
Gordon, Roger H. and Jeffrey K. MacKie-Mason. 1995. "Why Is There Corporate Taxation in a Small Open Economy? The Role of Transfer Pricing and Income Shifting.” In M. Feldstein, J.R. Hines, Jr. and R.G. Hubbard (eds.), The Effects of Taxation on Multinational Corporations. Chicago: University of Chicago Press.

Haufler, Andreas and Guttorm Schjelderup. 2000. “Corporate Tax Systems and Cross Country Profit Shifting." Oxford Economic Papers 2: 306-25.

Hines, James. R. 2005. “Do Tax Havens Flourish?” In J. Poterba (ed.), Tax Policy and the Economy. Vol. 19. National Bureau of Economic Research and MIT Press.

Hines, James R. and Eric Rice. 1994. "Fiscal Paradise: Foreign Tax Havens and American Business.” Quarterly Journal of Economics 109: 149-82.

Hong, Qing and Michael Smart. 2005. "In Praise of Tax Havens: International Tax Planning and Foreign Direct Investment.” Mimeo, University of Toronto, May 25.

Janeba, Eckhard and Wolfgang Peters. 1999. “Tax Evasion, Tax Competition, and the Gains from Nondiscrimination: The Case of Interest Taxation in Europe." The Economic Journal 109: 93-101.

Janeba, Eckhard and Michael Smart. 2003. "Is Targeted Tax Competition Less Harmful than its Remedies?" International Tax and Public Finance 10: 259-80. 
Keen, Michael. 2001. "Preferential Regimes Can Make Tax Competition Less Harmful." National Tax Journal 54: 757-762.

Marceau, Nicolas, Steve Mongrain, and John D. Wilson. 2006. "On the Efficiency of Tax Havens," Mimeo, Michigan State University.

Mayshar, Joram. 1991. "Taxation with Costly Administration." Scandinavian Journal of Economics 93(1): 75-88.

Palan, Ronen. 2002. "Tax Havens and the Commercialization of State Sovereignty." International Organization, 56(1): 151-176.

Slemrod, Joel and Shlomo Yitzhaki. 2002. "Tax Avoidance, Evasion, and Administration.” In A. Auerbach and M. Feldstein (eds.), Handbook of Public Economics, Vol. 3, Elsevier Science B.V.

Wilson, John D. 1999. “Theories of Tax Competition.” National Tax Journal 52: 269304.

Wilson, John D. 2005. “Tax Competition with and without Preferential Treatment of a HighlyMobile Tax Base.” In J. Alm, J. Martinez-Vazquez, and M. Rider (eds.), The Challenges of Tax Reform in a Global Economy, Springer. 


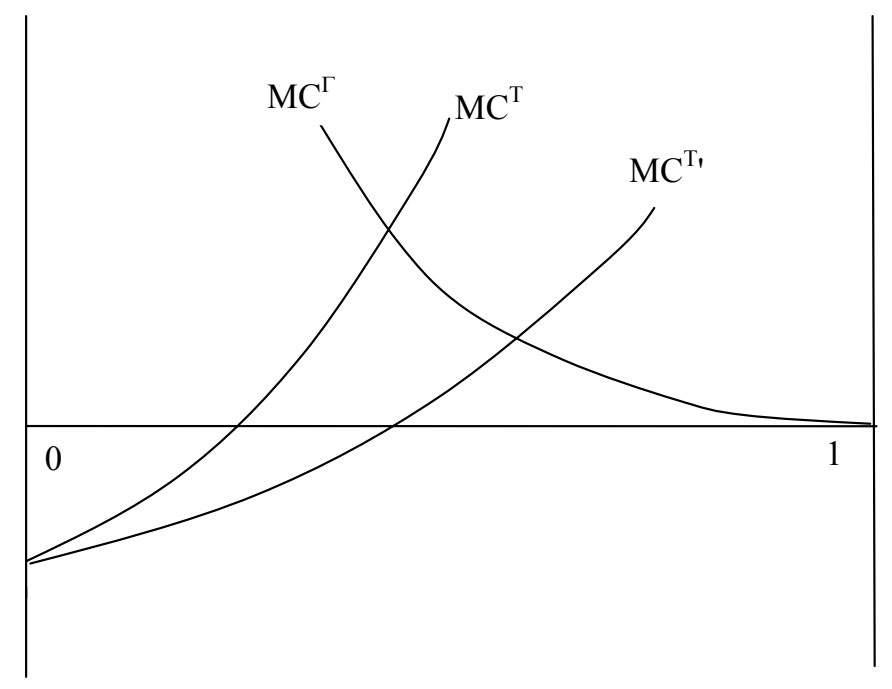

Figure 1

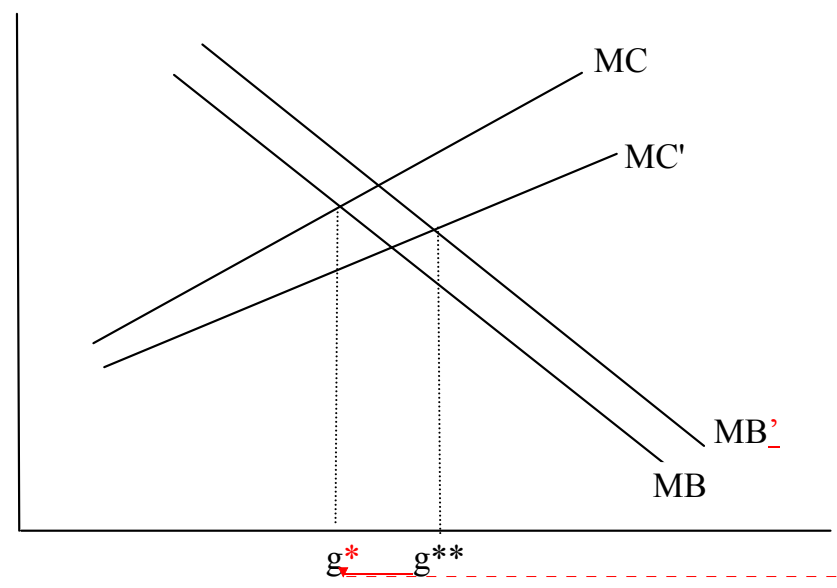

Deleted: *

Figure 2 